\title{
Estimation of operating costs and energy consumption in beneficiation of alluvial gold deposits
}

\author{
Ruslan Seryi ${ }^{1 *}$ and Vladimir Alekseev ${ }^{1}$ \\ ${ }^{1}$ Mining Institute FEB RAS, 51 Turgenev st., Khabarovsk, 680000, Russia
}

\begin{abstract}
There are many scientific and practical works related to the identification and assessment of factors affecting the efficiency of beneficiation of placer sands at the sluice box, while the energy consumption of the beneficiation process, as well as assessing the efficiency of the sand screening process and the cost of maintaining the devices, is given little attention. Studies of the energy consumption of sand washing, carried out at several alluvial deposits, made it possible to identify the most energyconsuming devices, as well as to compare the energy expended for transporting rock through processing plants and to provide solid to liquid ratio during beneficiation at sluice boxes.
\end{abstract}

\section{Introduction}

The share of alluvial deposits containing fine and plate-like gold is constantly increasing, and deposits with a high content of clay particles, heavy minerals, as well as technogenic deposits are also involved in mining. As a result, there is an increase in metal losses and, in general, a decrease in the efficiency of the development of such deposits [1-6].

For the extraction of placer gold, jigging machines, centrifugal concentrators, screw separators have been developed and tested at many enterprises, which make it possible to increase the recovery of precious metals with a grain size of less than $0.2 \mathrm{~mm}$, but still in Russia and abroad the main share of placer gold is extracted at washing devices equipped with sluices [7-11].

Effective development of natural and technogenic deposits is possible only if new technological solutions are used the choice of optimal design and technological indicators of mining and processing equipment (washing devices), depending on the combination of influencing natural, design and technological factors [12-14].

There are many scientific and practical works related to the identification and assessment of factors affecting the efficiency of processing of placer sands at the sluice boxes [15-17], while the energy consumption of the beneficiation process, as well as the assessment of the efficiency of the sand screening process and the cost of maintaining the devices (operating costs) are given little attention.

\footnotetext{
*Corresponding author: Ruslan_SSR@mail.ru
} 


\section{Analysis of instrument operation}

A Deroker-type washing device based on a lamellar screen GGM-3 and PPM-5 with a productivity of 70 and $100 \mathrm{~m}^{3} / \mathrm{h}$ is intended for washing and beneficiation of gold-bearing sands during the development of bouldery placer deposits. Since the beginning of the 2000s, these devices have become widespread in placer gold mining, while they are often used not only when mining bouldery placers, but also in deposits where boulders are insignificant, and sands with a size of less than $30 \mathrm{~mm}$ are prevailing, containing dusty clay fraction. As a result, the productivity decreases by $15-30 \%$, the load on the sluices increases, which in turn leads to additional losses of gold.

The main problems faced by the majority of subsoil users when operating such devices are the stretching of the belts, their premature wear during operation, which increases the size of the sands eaten at the sluice, especially flattened stones, the size of which along the long side can reach $15-20 \mathrm{~cm}$.

The installed drive capacity of the oil station GGM-3 is $30 \mathrm{~kW}$, PPM-5 is $45 \mathrm{~kW}$; the actual consumption during operation is about $70 \%$ of the installed capacity. Pumping units (often based on a 1D 1250-63 pump with a diesel drive) consume approximately 70-90 kW (GGM-3) and 90-120 kW (PPM-5). A large amount of water on the sluice attachments of such devices is necessary to remove large and especially flattened pebble fractions. To exclude bucking on pumps with a diesel drive, the pump speed is increased, as a result of which the energy consumption of the work is sharply increased, which does not contribute to acceptable rates of gold recovery at the sluices, and when sands with the presence of fine and fine gold are mined, losses increase even more. To reduce the loss of gold on the devices of the Deroker-type, a scheme was tested with the division of the flow of deep filling sluices (DFS) into two flows: oversize and undersize (Fig. 1). Thus, without increasing the dimensions of the attachment and the height of the device, hinged sieves are placed on the sucker-rod pumping pump, a technological gap remains between the bottom of the well and the sieves. Carpets and expanded metal (expanded steel sheet) are laid at the bottom of the deck or ladder stencils 20-30 mm high. The pulp, passing through the sieves, is screened out according to the size class of 4-7 mm, and then in the undersize space the beneficiation process takes place as on fine-fill sluices (FFS).

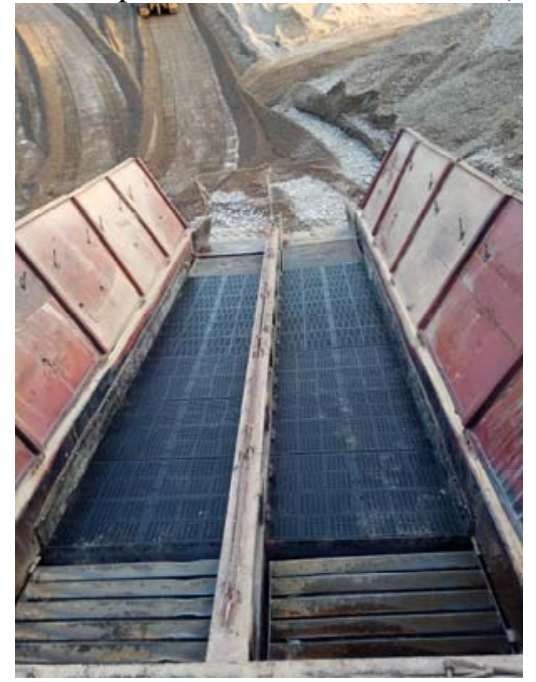

a)

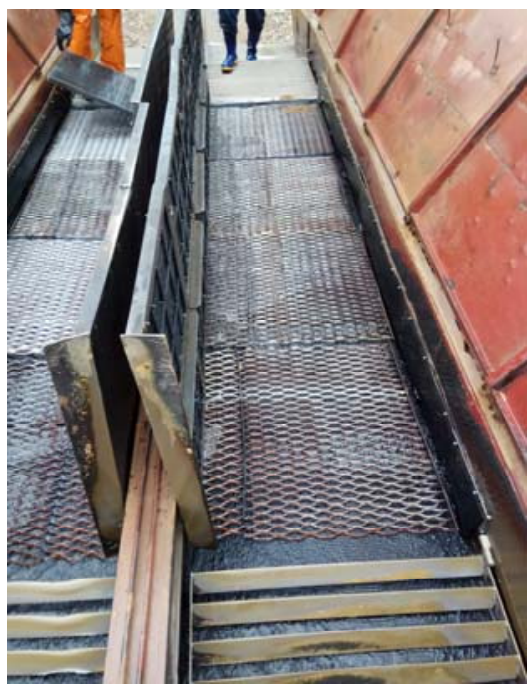

b)

Fig. 1. A variant of the modernization of the PPM-5 sluice attachment due to the separation of the flow and beneficiation of the undersize fraction at the sluices of fine filling. a) - in working position, b) - during shooting. 
As a result of the modernization of the sluice at the gold deposit of the river Buor-Sala noted an increase in gold yield in the class $-0.2 \mathrm{~mm}$ by $40 \%$, as well as a decrease in the gold content in dredging tailings.

Industrial hydraulic sluice devices (HSD-50, HSD-75), as well as suction dredgers SDD-100, remain quite common, but their share in alluvial gold mining is gradually decreasing. They are considered to be among the most energy consuming. The HSD-50 device is equipped with a 1D 1250-63 pump with an installed power of $290 \mathrm{~kW}$, and the HSD-100 device works in tandem with a dredge pump with a power of about $360 \mathrm{~kW}$. The feeding of sand by the elevator has a limited capacity and requires constant repair of the elevator inserts and the first nozzle. On average, worn parts are replaced every 7-12 days. When sand is supplied to the device by a dredger, the productivity doubles, while the energy consumption also more than doubles. Washing sand on dredging devices is accompanied by frequent downtime due to the repair (restoration) of worn parts, and the use of imported dredgers, such as "Warman", allows to work out the washing season without stopping to restore the working parts, but the cost of such installations are much higher.

Beneficiation on devices of this type occurs according to a two-stage scheme (DFS and FFS). The gain due to the extraction of fine and thin metal on such devices is provided mainly due to the FFS. To ensure the efficient operation of the FFS, it is necessary to screen the sands on a limited length of the sowing part of the sluices, ensuring the specified operating parameters of the sluices (solid to liquid ratio, specific load and flow rate).

A proven solution in this matter is to change the design of the sowing surface, including the installation of sieves with a solid surface in the DFS (Fig. 2). The sieves are installed with increasing mesh size downstream. This solution provides a more uniform load on the FFS. A laminar mode of operation is created, sifting first of all minerals with a high specific gravity and gold, thus not overloading the sluice with rock. As a result of such modernization, there is an increase in the yield of gold or platinum on the oil-and-gas pump, the overall losses are reduced by 4-20\%, and in some cases even more.

So, when upgrading the SDD-130 industrial device at the River Worgolan deposit, was possible to more than halve the platinum content in the tailings of the industrial instrument. At the same time, the replacement of metal screens with new polyurethane sieves reduced operating costs by more than 200 thousand rubles per year.

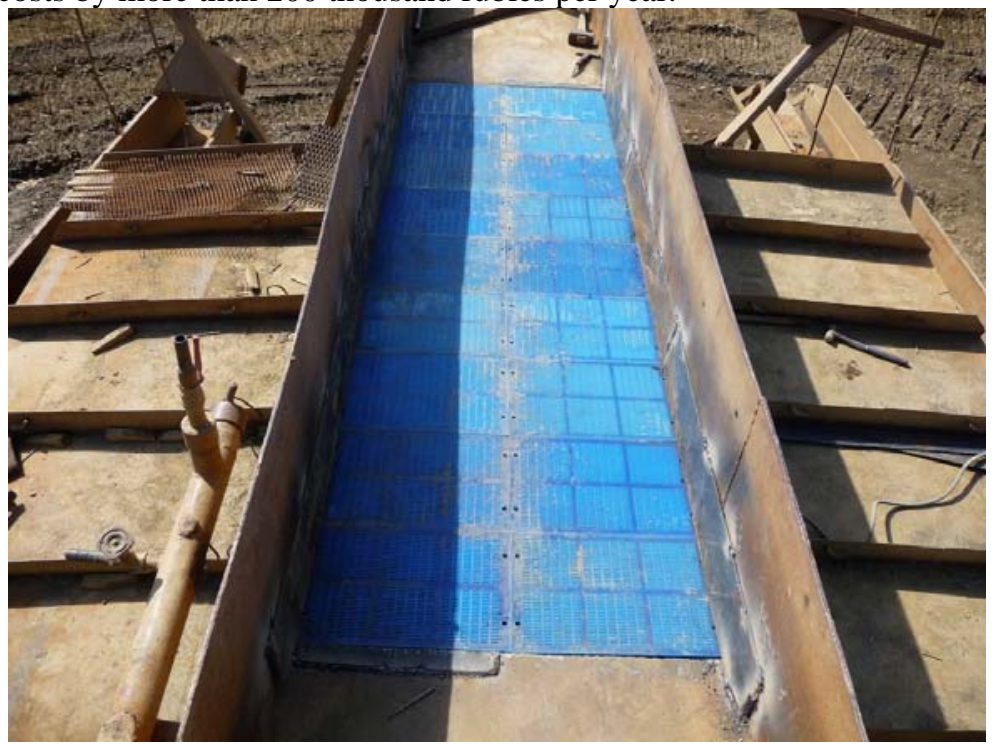

Fig. 2. The tail section of the HSD-50 at the Stream Bolotistiy placer gold deposit with installed polyurethane sieves above the DFS feeder bins 
Industrial devices based on vibrating screens GIT-42, GIT-52 and GIT-62

Over the past few years, this type of washing devices has become widespread in placer deposits. A distinctive feature of this device is its low cost in comparison with the BSB (barrel sluice box), SB (scrubber-butars), GGM, PPM and HSD devices, as well as high productivity for the original sands.

It is worth noting the low energy consumption of the device itself. So on the GIT-52 device with a sand capacity of more than $100 \mathrm{~m}^{3} / \mathrm{h}$, an electric motor with a capacity of only $18 \mathrm{~kW}$ is installed. The design of the device is rather simple and reliable, and the main elements subject to strong abrasive wear are the sowing surfaces of the upper and lower tier of sieves.

The experience of using metal wire screens shows that with a high open area and low cost, their service life does not exceed several days. As a result, constant downtime of the device for changing sieves, as well as the need to purchase new ones, reduces productivity and increases operating costs. Round metal sieves, depending on the steel grade, are operated much longer, but due to the large metal thickness (usually $20 \mathrm{~mm}$ on the upper tier, 10$15 \mathrm{~mm}$ on the lower tier), they weigh much more and tend to clog during operation. For sieves of the lower tier, such an important indicator as the free area often does not exceed $20 \%$. As a result, the performance of the device decreases. The most well-proven, especially when screening into small size classes, are rubber and polyurethane sieves, which have a good free cross-section (25-39\%), have a self-cleaning effect (do not clog) and are characterized by an increased service life (in comparison with metal ones - 2-4 times).

Fig. 3 shows the lower tier of the GIT-62 industrial device with installed polyurethane sieves that worked for two washing seasons, during which more than 450 thousand $\mathrm{m}^{3}$ of sands were washed.

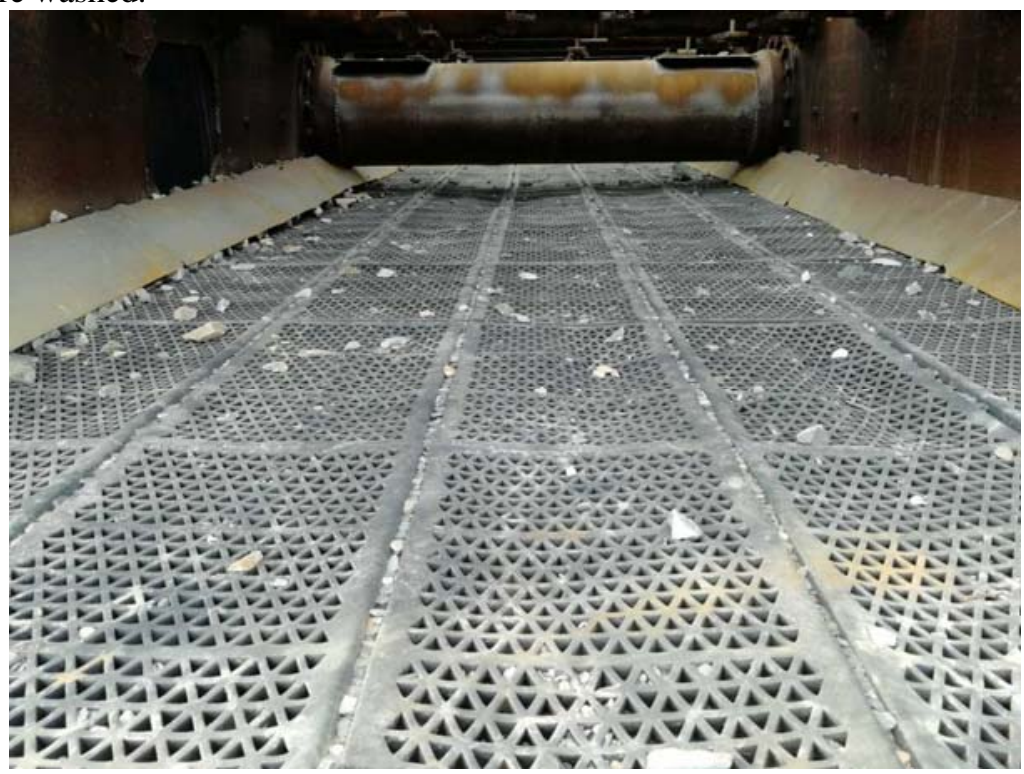

Fig. 3. GIT-62 device with polyurethane sieves of the lower tier

Barrel devices and scrubber-butar's

This type of device remains one of the most common in placer gold mining. There are many modifications of such devices; more than 10 factories in Russia produce them. In terms of energy consumption for an industrial device with a capacity of $100 \mathrm{~m}^{3} / \mathrm{h}$, the power of the rotation drive of the scrubber-butar is from 30 to $55 \mathrm{~kW}$, depending on the rotating supports (metal, pneumatic wheels, etc.). The pumping unit, as a rule, is selected depending on the size of the fraction to be concentrated and the number of sluices; the most frequently 
installed pumps are 1D630-90 (980 rpm), 1D-800-56a (1450 rpm) with a capacity of 81 and $132 \mathrm{~kW}$, respectively. On average, pump consumption for a device with a capacity of 100 $\mathrm{m}^{3} / \mathrm{h}$ is about $100-110 \mathrm{~kW} / \mathrm{h}$.

The entire inner surface of the scrubber-butar on large productive devices has a surface of more than $50 \mathrm{~m}^{2}$, which is subject to constant wear during operation. In order to prevent complete wear and tear of the scrubber-butar structure, constant surfacing of metal sieves and lining are performed using a large amount of welding. All this leads to additional equipment downtime, reducing the technical availability factor. A good proven solution would be to install removable polyurethane lining elements and polyurethane sieves throughout the entire inner surface of the device, which completely eliminates wear of the scrubber-butar's bearing elements, reduces its weight and reduces operating costs by about half. Replacement of such structural elements is required once every 2-4 season and is done quickly, so the investment pays off quickly. In fig. 4 the BSB-100 device is shown, it is designed and manufactured by employees of the Mining Institute of the FEB RAS. The inner surface of the scrubber part was completely lined, polyurethane thresholds were installed on annular stiffeners; in the sowing part polyurethane sieves are mounted (Fig. 5). All this made it possible to completely prevent wear of the bearing elements of the scrubber-butar.

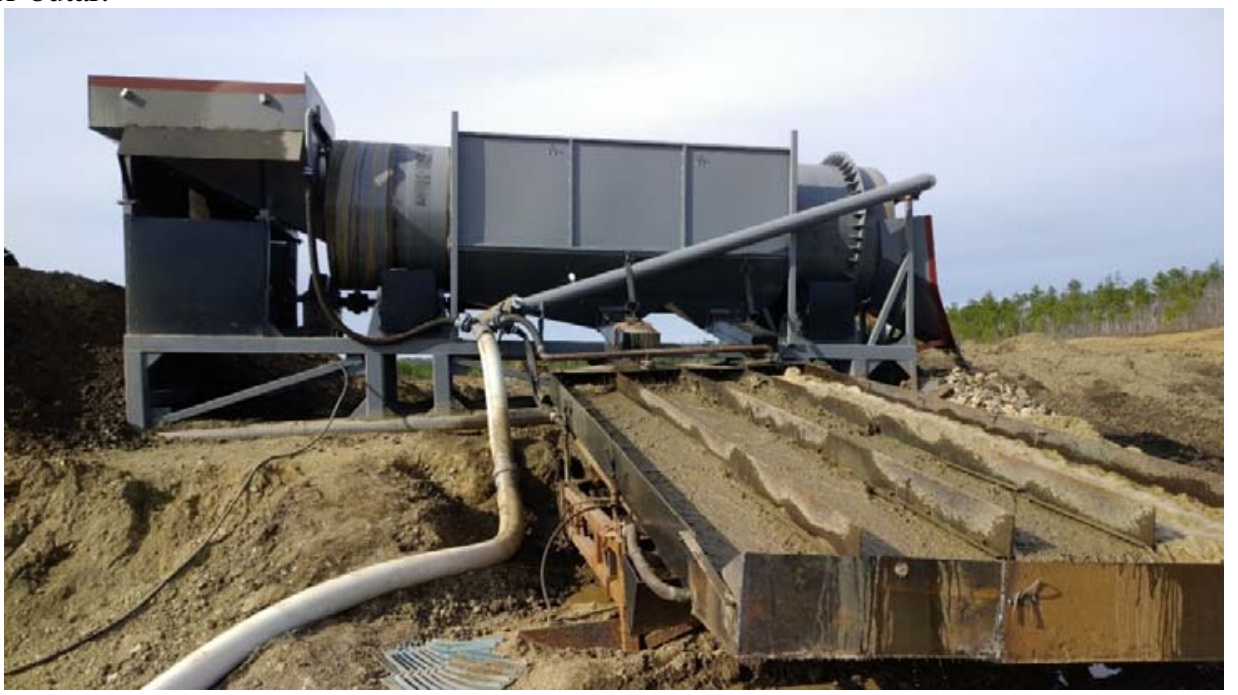

Fig. 4. Industrial device BSB-100 operating at an alluvial gold deposit in the Amur Region

Maintenance costs for the same device at different enterprises can vary greatly depending on many factors, such as: the presence or absence of repair shops for prompt repair of devices, the quality of repairs performed at the beginning of the season, the quality of materials used in production equipment at various factories. For example, the manufacture of parts subject to abrasive wear from steel grade C3 leads to its rapid wear and requires constant repair. Table 1 presents an aggregated calculation of the energy consumption of sand washing and operating costs for the sluice washing devices most commonly used in placer gold mining. 


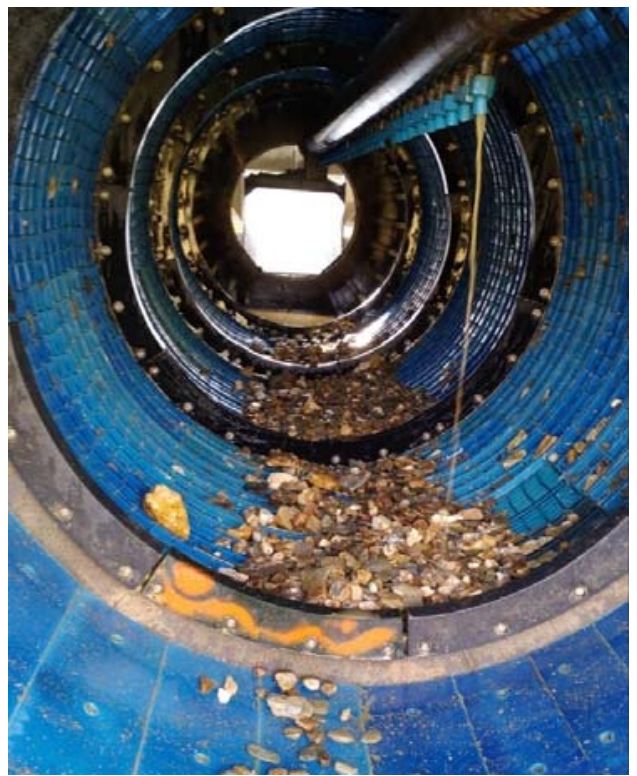

Fig. 5. The inner surface of the scrubber-butar of the BSB-100 device

Table 1. Operational indicators of the washing devices

\begin{tabular}{|l|c|c|c|c|c|c|}
\hline \multicolumn{1}{|c|}{ Indicator } & Units & PPM-5 & GIT-52 & HSD-50 & SDD-100 & BSB-100 \\
\hline Passport performance & $\mathrm{m}^{3} / \mathrm{h}$ & 100 & 200 & 50 & 100 & 100 \\
\hline Actual performance & $\mathrm{m}^{3} / \mathrm{h}$ & 70 & 100 & 40 & 90 & 90 \\
\hline Installed drive power & $\mathrm{kW}$ & 45 & 18 & 0 & 368 & 55 \\
\hline $\begin{array}{l}\text { Used pump brand, pump } \\
\text { speed }\end{array}$ & $\mathrm{rpm}$ & $\begin{array}{c}1 \mathrm{D}-1250- \\
63,980\end{array}$ & $\begin{array}{c}1 \mathrm{D}-630-90, \\
1000\end{array}$ & $\begin{array}{c}1 \mathrm{D}-1250- \\
63,1500\end{array}$ & $\begin{array}{c}1 \mathrm{D}-1250-63, \\
1500\end{array}$ & $\begin{array}{c}1 \mathrm{D}-630-90, \\
1000\end{array}$ \\
\hline Installed pump power & $\mathrm{kW}$ & 90 & 80 & 290 & 290 & 80 \\
\hline Total installed power & $\mathrm{kW}$ & 135 & 98 & 290 & 658 & 135 \\
\hline $\begin{array}{l}\text { Total daily consumption } \\
\text { of diesel fuel }\end{array}$ & tonnes & 0.51 & 0.39 & 1.04 & 2.12 & 0.50 \\
\hline Appliance weight & tonnes & 36.4 & 17 & 25 & 35 & 22 \\
\hline $\begin{array}{l}\text { Price of the device with- } \\
\text { out VAT }\end{array}$ & $\begin{array}{c}\text { Million } \\
\text { roubles }\end{array}$ & 9 & 5.5 & 3.7 & 12 & 7 \\
\hline Annual operating costs & $\begin{array}{c}\text { Million } \\
\text { roubles }\end{array}$ & 3.5 & 0.5 & 0.8 & 5 & 1 \\
\hline $\begin{array}{l}\text { Seasonal productivity, } \\
\text { work 20 h/day, 150 } \\
\text { days/year }\end{array}$ & thou- & 210 & 300 & 120 & 270 & 270 \\
\hline $\begin{array}{l}\text { Seasonal fuel consump- } \\
\text { tion, 150 days }\end{array}$ & tonnes & 76.5 & 58.3 & 155.3 & 317.6 & 74.7 \\
\hline $\begin{array}{l}\text { Seasonal expenses (fuel } \\
\text { and lubricants 50 thou- } \\
\text { sand rubles/ ton, spare } \\
\text { parts, depreciation 20\%) }\end{array}$ & $\begin{array}{l}\text { Million } \\
\text { roubles }\end{array}$ & 9.1 & 4.5 & 9.3 & 23.3 & 6.1 \\
\hline $\begin{array}{l}\text { Specific fuel consump- } \\
\text { tion }\end{array}$ & $\mathrm{kg} / \mathrm{m}^{3}$ & 0.36 & 0.19 & 1.29 & 1.18 & 0.28 \\
\hline $\begin{array}{l}\text { Unit operating costs of } \\
\text { the device per 1 m3 of } \\
\text { sand }\end{array}$ & rub & 43 & 15 & 78 & 86 & 23 \\
\hline $\begin{array}{l}\text { Energy consumption of } \\
\text { water supply from total } \\
\text { energy consumption }\end{array}$ & $\%$ & 66.7 & 81.6 & 100.0 & 44.1 & 59.3 \\
\hline
\end{tabular}




\section{Conclusions}

It can be seen from the data in the table that the highest specific fuel consumption is for devices of the elevator type HSD-50 and the dredger SDD-100 (more than $1 \mathrm{~kg} / \mathrm{m}^{3}$ ). But the use of suction dredgers by lifting the pulp to a height of up to $30 \mathrm{~m}$ in most cases will make it possible to abandon the transport scheme for the supply of sands. The smallest indicator of specific fuel consumption is for devices based on a vibrating screen (about $0.2 \mathrm{~kg}$ $/ \mathrm{m}^{3}$ ), for BSB and PPM devices (0.28 and $0.36 \mathrm{~kg} / \mathrm{m}^{3}$, respectively).

A characteristic feature of almost all types of devices is that the main energy (from $60 \%$ and more) spent when washing sands falls on the water supply. The HSD devices use a pump to supply sand with an airlift, so all the pump's energy is spent for washing, feeding the sands to the device and enriching them at the sluices.

Deroker-type devices have high operating costs associated with the high cost of highly wear belts. On such devices, breakdowns often occur, such as breakage of the edges of the bands, breakage of hydraulic cylinder hoses, etc. This device has a very narrow area of application (boulder deposits with medium and large gold) and their use in deposits even with a small content of clay in sands leads to a sharp increase in gold losses, but in practice there is a picture of their widespread use even in deposits with fine gold. Reducing metal losses is possible due to the modernization of factory sluice attachments.

HSD devices are still quite widespread (there are enterprises where the park of such devices is $12-15$ pcs.), but due to their high energy intensity (high cost of diesel fuel), as well as low productivity, their share in placer gold mining is constantly decreasing.

SDD devices, although they are quite energy-intensive devices, at the same time ensure the lifting of sands along the slurry pipeline and their transportation over long distances, as well as good indicators of disintegration efficiency in comparison with most of the used devices and are comparable to scrubber-butters. High operating costs are associated, as a rule, with the replacement of expensive imported dredgers, drive motors, slurry pipelines.

Devices based on the vibrating screen GIT are highly popular for several reasons: high productivity (up to $200 \mathrm{~m}^{3} / \mathrm{h}$ ), relatively low cost, simple design (the entire mechanical part of the device consists of a motor, a coupling and an eccentric shaft on two bearings). The use of modern modular sieves makes it possible not only to solve the problem of their wear, clogging and, as a result, equipment downtime, but also to use them on boulders, which is a good alternative to expensive in operation devices of the Deroker-type. The main disadvantage of such devices is their low disintegrating ability.

Devices based on scrubber-butar (BSB, SB), according to the authors, are the most versatile, since they provide high productivity and good disintegration for medium-washed sands, have a low specific fuel consumption (about $0.3 \mathrm{~kg} / \mathrm{m}^{3}$ ). The use of removable lining elements and polyurethane sieves will reduce the downtime of the device for surfacing and restoration, protects the load-carrying elements of the scrubber-butar structure, which will allow it not to be changed later for several seasons.

\section{Bibliography}

1. E.A. Khrustalev, Gold and Technology, 2, 20-24 (2015)

2. V.S. Litvintsev, Journal of Mining Science, 1, 118-126 (2013)

3. Yu.A. Mamaev, V.S. Litvintsev, V.S. Alekseev, Bulletin of higher educational institutions. Mining magazine, 8, 135-145 (2011)

4. G.S. Mirzekhanov, Z.G. Mirzekhanova, Resource potential of technogenic formations of alluvial gold deposits (Moscow, MAKS Press, 2013)

5. R.S. Seryi, V.S. Alekseev V.S., P.P. Sas, Non-Ferrous Metals, 2, 31-35 (2017) 
6. V.S. Litvintsev, V.S. Alekseev, I.A. Kradenykh, Mine surveying and subsoil use, 5, 2129 (2017)

7. W.P. LeBarge, M.G. Nordling, Yukon Geological Survey (2011)

8. S.Van Loon, J.D. Bond, Yukon Geological Survey (2014)

9. O. John. Marsden., Society for Mining, Metallurgy, and Exploration (2006)

10. V.S. Litvintsev, Journal of Mining Science, 1, 190-194 (2012)

11. V.S. Litvintsev, Euraslan mining, 1, 7-11 (2014)

12. V.S. Alekseev, R.S. Seryi, A.A. Sobolev, Beneficiation of ores, 5, 13-18 (2019)

13. V.S. Alekseev, T.S. Banshchikova, Journal of Mining Science, 4, 159-164 (2017)

14. T.S. Banshchikova, N.A. Leonenko, V.S. Alekseev, Beneficiation of ores, 6, 32-37 (2017)

15. R.S. Seryi, Mine surveying and subsoil use, 6, 20-22 (2014)

16. R.S. Seryi, V.V. Taganov, K.V. Gevalo, Mining Journal, 10, 49-52 (2018)

17. R.S. Seryi, V.S. Alekseev, P.P. Sas, Gold and Technology, 1, 104-107 (2015) 